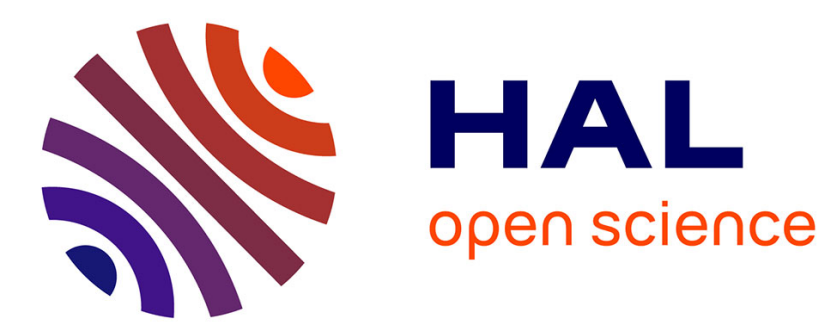

\title{
Estimated UV doses to psoriasis patients during climate therapy at Gran Canaria in March 2006
}

\author{
L. T. N. Nilsen, E. Søyland, A. L. Krogstad
}

\section{To cite this version:}

L. T. N. Nilsen, E. Søyland, A. L. Krogstad. Estimated UV doses to psoriasis patients during climate therapy at Gran Canaria in March 2006. Atmospheric Chemistry and Physics Discussions, 2008, 8 (1), pp.1-19. hal-00303221

\section{HAL Id: hal-00303221 \\ https://hal.science/hal-00303221}

Submitted on 2 Jan 2008

HAL is a multi-disciplinary open access archive for the deposit and dissemination of scientific research documents, whether they are published or not. The documents may come from teaching and research institutions in France or abroad, or from public or private research centers.
L'archive ouverte pluridisciplinaire HAL, est destinée au dépôt et à la diffusion de documents scientifiques de niveau recherche, publiés ou non, émanant des établissements d'enseignement et de recherche français ou étrangers, des laboratoires publics ou privés. 
UV doses during psoriasis climate therapy at Gran

Canaria

\section{Estimated UV doses to psoriasis patients during climate therapy at Gran Canaria in March 2006}

L. T. N. Nilsen ${ }^{1}$, E. Søyland ${ }^{2}$, and A. L. Krogstad ${ }^{2,3}$

${ }^{1}$ Norwegian Radiation Protection Authority, Østerås, Norway

${ }^{2}$ Section for Climatotherapy, Department of Reumatology, Rikshospitalet University Hospital, Oslo, Norway

${ }^{3}$ Department of Dermatology, Rikshospitalet University Hospital, Oslo, Norway

Received: 3 December 2007 - Accepted: 3 December 2007 - Published: 2 January 2008

Correspondence to: L. T. N. Nilsen (lill.tove.nilsen@nrpa.no)

L. T. N. Nilsen et al.

Title Page

Abstract

Conclusions

Tables

14

4

Back
Introduction

References

Figures

$\rightarrow$

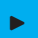

Close

Full Screen / Esc

Printer-friendly Version

Interactive Discussion 


\section{Abstract}

Psoriasis is a chronic inflammatory disease involving about $2-3 \%$ of the Norwegian population. Sun exposure has a positive effect on most psoriasis lesions, but ultraviolet (UV) radiation also causes a direct DNA damage in the skin cells and comprises a 5 carcinogenic potential. UV exposure on the skin causes a local as well as a systemic immune suppressive effect, but the relation between sun exposure and these biological effects is not well known. In March 2006 a study was carried out to investigate possible therapeutic outcome mechanisms in 20 psoriasis patients receiving climate therapy at Gran Canaria. This paper presents estimates of their individual skin UV-doses based on UV measurements and the patients' diaries with information on time spent in the sun.

On the first day of exposure the patients received on average 5.1 Standard Erythema Doses (SED: median=4.0 SED, range 2.6-10.3 SED) estimated to the skin. During the 15 days study they received 165.8 SED (range 104.3-210.1 SED). The reduction in improvement and the UV dose. The UV doses were higher than those found from climate therapy studies at other locations. It seems beneficial to use more strict exposure schedules that consider the available UV irradiance, depending on time of the day, time of the year and weather conditions.

\section{Introduction}

Psoriasis is a chronic inflammatory disease involving about $2-3 \%$ of the Norwegian population. Plaque psoriasis, the most common form of psoriasis, typically appears as raised areas of inflamed skin covered with silvery white scaly skin. The severity is usually graded as mild, moderate or severe. The Psoriasis Area Severity Index (PASI) is the most widely used measurement tool for psoriasis. The PASI score varies from 0 (no symptoms) to a maximum of 72 , reflecting the surface area affected and
UV doses during psoriasis climate therapy at Gran

Canaria

L. T. N. Nilsen et al.

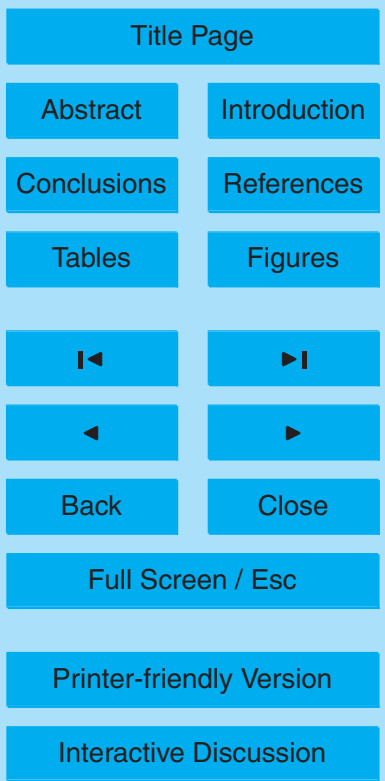


the severity of the lesions, i.e. the redness, thickness and scaling (Fredriksson and Pettersson, 1978).

Ultraviolet (UV) radiation from the sun is an effective and natural treatment method for psoriasis. The cell proliferation in the basal layer of the skin is increased in the 5 psoriasis lesions and the UV radiation slows down this process. Furthermore, the combination of UVB-induced apoptosis, increased secretion of anti-inflammatory cytokines and decreased trafficking to the skin, may also explain the beneficial effects of UVB treatment on psoriasis and why disease remission can sometimes be sustained for a prolonged period (Sigmundsdottir et al., 2003, 2005). Climate therapy has been 10 offered to psoriasis patients since many years at low latitude locations such as in the Dead Sea resort and the Canary Islands, and at high altitude locations, e.g. in Davos, Switzerland. Norwegian psoriasis patients have been offered climate therapy since late 1976 (NOU, 2000). Today, this treatment option is administrated by the Section for Climatotherapy, Department of Reumatology at the Rikshospitalet University Hospital 15 in Oslo, Norway. The patients are treated at the Norwegian Health Centre at Valle Marina, Gran Canaria, for 3 weeks in the period January to June and September to the beginning of December. The therapy is supervised by a resident dermatologist, nurses and physiotherapists. It focuses on UV exposure paralleled by educational courses designed to help the patients in coping with the chronic aspects of psoriasis and to highlight the importance of diet and physical activity.

The original schedule for the 28 day Dead Sea climate therapy of psoriasis called for a sun exposure of 6-7 $\mathrm{h}$ daily, following shorter acclimatization sessions during the first week (Abels and Rose, 1995). However, recent studies from the Dead Sea area have reported $69.7-86 \%$ improvement with respect to PASI score in patients receiving only $253 \mathrm{~h}$ daily sun exposure (excluding the noon hours) for 4 weeks in the period March to November (Even-Paz et al., 1996 and Even-Paz and Efron, 2003). They monitored the ambient UV dose in terms of Standard Erythema Dose (SED), and these results were achieved for ambient UV doses higher than 170 SED. Treatment in December with an ambient dose of 120 SED showed only $33 \%$ improvement.

\section{ACPD}

$8,1-19,2008$

UV doses during psoriasis climate therapy at Gran Canaria

L. T. N. Nilsen et al.

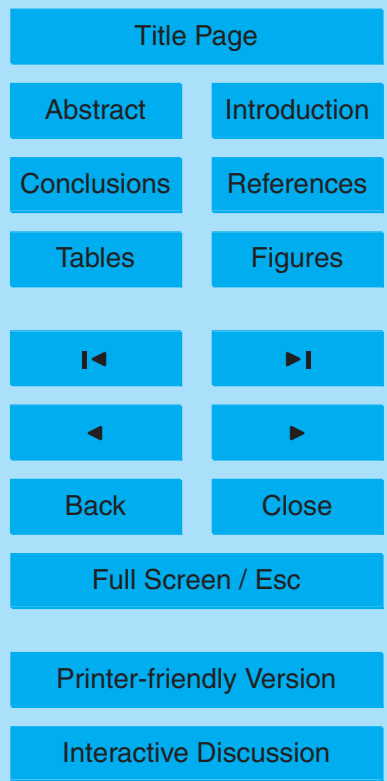


Other studies have also estimated or measured UV doses in relation to regular climate therapy. Vocks et al. (1989) found a mean UVB dose of $1.04 \mathrm{~J} / \mathrm{cm}^{2}$ (50 Minimal Erythema Doses, MED) for a 6 weeks high altitude treatment in Davos, Switzerland. Kushelevsky et al. (1998) found a mean ambient UV dose of $3.11 \mathrm{~J} / \mathrm{cm}^{2}$ or 148 MED for 5 skin type IV patients after 4 weeks treatment by the Dead Sea. Snellman et al. (1992) found from personal dosimeters a mean ambient dose of about $3.3 \mathrm{~J} / \mathrm{cm}^{2}$ after a 4 week treatment and on average about $1.3 \mathrm{~J} / \mathrm{cm}^{2}$ to the skin.

This paper will present estimated UV doses for the psoriasis patients participating in a study to investigate the influence of the sun exposure on local and systemic immuno10 logic effects. In particular, cytokines, T cell profiles, vitamin D and its metabolites were investigated. This report focuses specifically on the measurements of UV radiation that underlies the expected changes in the biological mechanisms.

\section{Material and methods}

The study was carried out in March 2006 at the Norwegian Health Centre at Valle 15 Marina, Gran Canaria $\left(27^{\circ} \mathrm{N}, 15^{\circ} \mathrm{W}\right)$. Climate therapy for psoriasis patients lasts for 21 days. The study period lasted for 15 of these 21 days, starting at 15 March 2006.

\subsection{Patient material}

The study included 20 patients (mean age 47.2 years, range 24-65, 6 females and 14 males) with moderate to severe psoriasis. PASI before climate therapy was 9.8 (mean, range 3.8-18.8). PASI scores were assessed by dermatologists before and after the sun exposure. The patients had stopped using any psoriasis medication 4 weeks before the study started. Two of the patients had skin type II and 18 had skin type III according to the Fitzpatrick classification (Fitzpatrick, 1988).

Blood samples and skin biopsies were taken before the sun exposure, after one day

\section{ACPD}

$8,1-19,2008$

UV doses during psoriasis climate

therapy at Gran

Canaria

L. T. N. Nilsen et al.

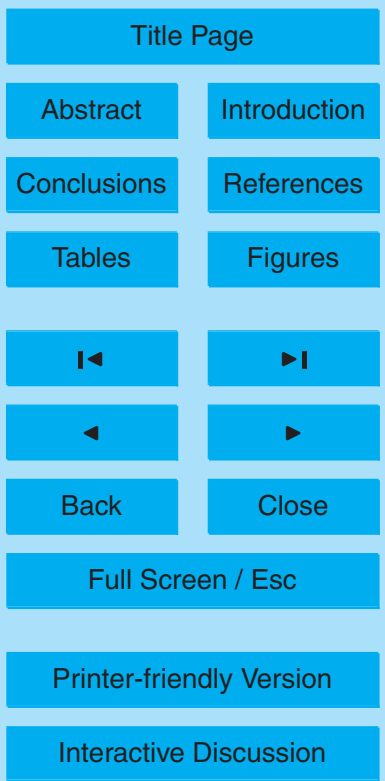


The patients followed a strict exposure schedule the first day of the study, exposing first the front side of the body for $30 \mathrm{~min}$, the back side for $30 \mathrm{~min}$, followed by $15 \mathrm{~min}$ exposure on each side in the period from about 11:00 and 13:00 LT. They were allowed to stay outside after lunch, but only if a proper amount $\left(2 \mathrm{mg} / \mathrm{cm}^{2}\right)$ of sunscreen with sun 5 protection factor (SPF) of 25 (Pediatrics Fotoprotector ISDN, 25B-10A-IR) was used for the whole body (Colipa, 2006). For the remaining days, the patients were advised to gradually increase the hours of exposure per day and only use sunscreen on locations easily burned. The patients registered time spent in the sun every day and for every 20 min interval from 09:00 to 17:00 LT, as well as use of sunscreen and type of SPF 10 factor.

\subsection{UV measurements}

Spectral UVB (280-315 nm), UVA (315-400 nm) and CIE-weighted UV irradiances were measured using two broadband instruments every hour from 09:00 to 17:00 LT every day from 15 to 29 March 2006. The CIE-action spectrum is a reference action spec15 trum for UV induced erythema in Caucasian human skin (McKinlay and Diffey, 1987) valid for the UV region from 250 to $400 \mathrm{~nm}$. One of the broadband radiometers (Solar Light Co PMA 2100) was used with two sensors, one (PMA 2101 UVB sensor) that roughly resembles the spectral responsivity of the CIE-action spectrum, and the other (PMA 2110 UVA sensor) with fairly flat spectral responsivity in the UVA waveband. 20 The other broadband instrument (Gigahertz-Optik GmbH X11 Optometer) was used with UVB and UVA sensors (XD-9501-4) both with fairly flat responsitivities. The Solar Light PMA sensors were calibrated against a spectroradiometer (Brewer\#185, measurement range $286.5-365 \mathrm{~nm}$, extended for UVA 365-400 nm) at Izaña, Tenerife, prior to the study. Measurements and calibration factors were provided by Mr. Alberto Recalibrated in February 2005 and compared with the QUASUME Unit (Quality Assurance of Spectral Ultraviolet Measurements in Europe, http://lap.physics.auth.gr/qasume/) in September 2005. The Gigahertz-Optik sensor readings were compared with those of

\section{ACPD}

$8,1-19,2008$

UV doses during psoriasis climate therapy at Gran Canaria

L. T. N. Nilsen et al.

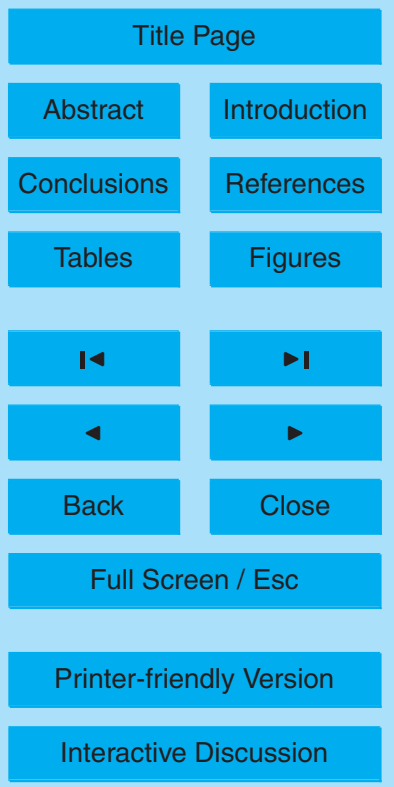

EGU 
the Solar Light sensors.

\subsection{UV dose estimates}

Spectral UVB and UVA irradiances, in addition to CIE-weighted UVB and UVA irradiances, were calculated for the whole period using a radiation transfer model, libRadtran 5 for irradiance calculations (Mayer and Kylling, 2005). The model was run for the following conditions: cloudless sky, albedo of 0.05 , sea level and ozone values from the TOMS satellite for the days 15 to 29 March 2006 (NASA, 2006).

The UV irradiances were adjusted according to the measurements taken at Valle Marina to account for the real weather situation and possible discrepancies from the model parameters, such as different albedo and aerosol amount.

Combining the calculated UV irradiances with the sun exposure time from the patients' diaries, UV doses were estimated for each patient after 1 day and after 15 days of sun exposure (according to when the blood samples and skin biopsies were taken as described in Sect. 2.1). Exposure times were calculated, on one hand, including all reported sun exposure, also when sunscreen was used. On the other hand, the exposure time using sunscreen the first day was excluded.

\section{Results}

The results are presented as spectral UVB and UVA doses, as well as CIE-weighted UVB, UVA and UV doses. Standard Erythema Dose (SED) is also presented $20 \quad\left(1 \mathrm{SED}=100 \mathrm{~J} / \mathrm{m}^{2}=0.01 \mathrm{~J} / \mathrm{cm}^{2}\right)$. All results are presented as mean of the doses as well as the range of doses (minimum-maximum). Median doses are presented when data are skewed. UV doses to each patient are set equal to the ambient UV doses divided by two, since only half the body can be exposed at any time. Doses are presented for the two cases; including and excluding exposure time when sunscreen was used the first day.

UV doses during psoriasis climate therapy at Gran

Canaria

L. T. N. Nilsen et al.

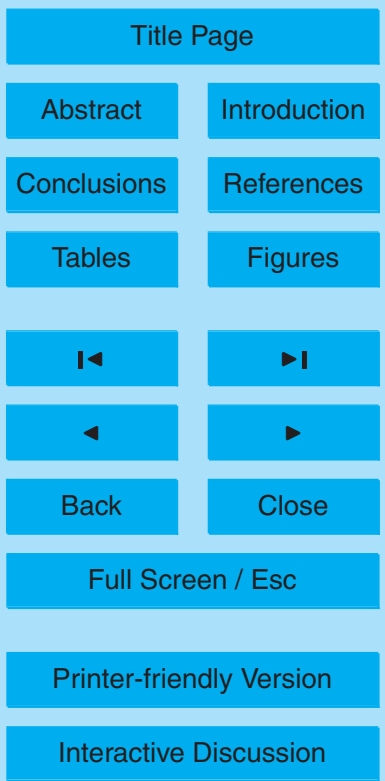


Sun exposure time each day and for each patient (Fig. 1) shows roughly a gradual increase throughout the treatment period, except for day 2 when all patients went by bus to and from the hospital in Las Palmas for taking blood samples and biopsies. When exposure using sunscreen the first day was excluded, the exposure time was 5 2.0/1.7 $\mathrm{h}$ (mean/median, range 1.0-4.0 h), whereas the corresponding number when sun exposure with sunscreen was included, was 3.6/3.7 h (range 2.0-5.0).

Table 1 shows the estimated UV doses to the skin after 1 day of sun exposure, both inclusive and exclusive time when using sunscreen. The patients sunbathing with sunscreen during the first day reported using approximately $30 \mathrm{ml}$ of cream. The estimated 10 UV doses for sun exposure when sunscreen effect was excluded varied between 2.6 and 10.3 SED and with a mean and median dose of 5.1 and 4.0 SED, respectively (Table 1 and Fig. 2). The mean dose was the same for the patients with skin type II and III. Seven patients exposed themselves to the sun without the prescribed sunscreen after lunch the first day and thereby received higher UV doses (Fig. 2). The po15 tential doses were markedly higher when time with sunscreen was included (Table 1). Fourteen out of the 20 patients reported erythema after the first day of sun exposure.

The mean dose after 15 days sun exposure was 165.8 SED if sunscreen use the first day was excluded (Table 2), 134.5 and 169.2 SED for the patients with skin type II and III, respectively. If sunscreen use the first day was included, the mean dose was 20 169.6 SED for all subjects combined. The patients reported using sunscreen mostly on body sites that could easily be burned, and the amount of sunscreen varied between 30 and $700 \mathrm{ml}$. The variation between minimum and maximum patient doses each day was large (Fig. 3). For the whole treatment period the accumulated doses varied by a factor 2 (Table 2 and Fig. 2).

25 All patients experienced a reduction in PASI score after the climate therapy to an average score of 2.4, range $0.4-6.9$. This can be expressed as a mean $72.8 \%$ (median $77.8 \%$, range $30.3-92.6 \%$ ) improvement in PASI score. The percentage improvement did not show significant correlation to the UV dose received by each patient (Fig. 4).

\section{$8,1-19,2008$}

UV doses during psoriasis climate therapy at Gran Canaria

L. T. N. Nilsen et al.

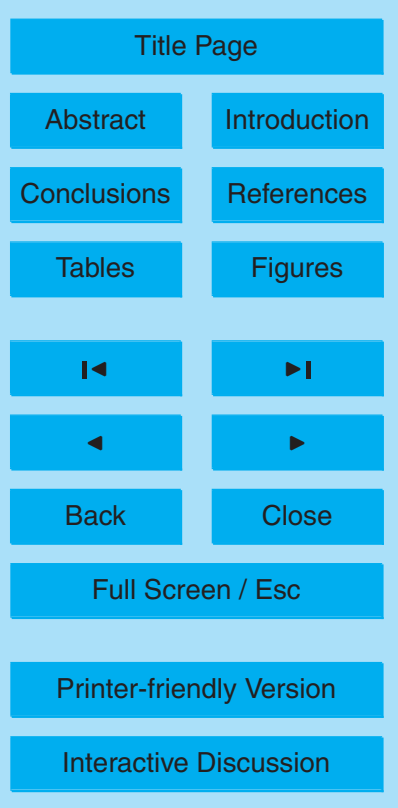




\section{Discussion and conclusions}

UV doses have been estimated for psoriasis patients receiving climate therapy at Gran Canaria in March 2006. The doses were estimated using a radiative transfer model corrected for local influence using broadband instruments positioned the Norwegian

5 Health Centre at Valle Marina. The UV doses were combined with sun exposure times registered by the patients each day.

When estimating UV doses, it is important to either measure UV irradiances on the actual location or use a simulation model with real weather conditions. These must be combined with indications of the time when patients have been exposed to the sun. On day 3, 8, 13 and 14 of this study, the patients spent relatively much time in the sun (Fig. 1), but the UV doses on these days were low (Fig. 3). The reason was more cloudy weather conditions and thereby lower UV intensities these days. Even though the patients were told to register all exposure time, the use of diaries is associated with uncertainties regarding registration of exposure time, e.g. whether 5-10 min walk to and from the nearest beach is included or not.

The assumption that the UV dose to the skin equals half the ambient dose is crucial. Different body sites have been shown to receive different proportions of UV, also depending on type of activity. Snellman et al. (1992) showed from personal dosimeter measurements that different body sites of psoriasis patients received from $22.2 \%$ (part of abdomen) up to 63.3\% (upper arm) of the ambient UV dose, with an average of $41.2 \%$ for all sites. Diffey et al. (1982) showed that sunbathing on the beach gave $80 \%$ of the ambient UV dose, while sight seeing only gave $17 \%$. Thieden et al. (2000) have shown that different body sites received $29-86 \%$ of the ambient dose when staying at a Danish beach with the highest doses on the shoulders. On average, the wrist received about half the ambient dose both at the beach and during holiday season in Scandinavia and Europe. Therefore, the assumption that our patients received half the ambient dose on each skin site seems to be appropriate as a first approximation.

Use of sunscreen also influences the UV exposure to the skin. The declared SPF fac-
UV doses during psoriasis climate therapy at Gran Canaria

L. T. N. Nilsen et al.

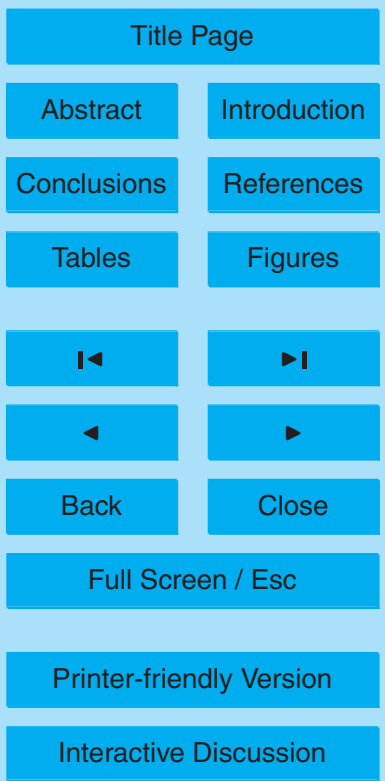


tor requires application of the sunscreen with a thickness of $2 \mathrm{mg} / \mathrm{cm}^{2}$ (Colipa, 2006). For an adult body that would be about $40 \mathrm{ml}$ (Siekmann and Aengenvoort, 2007). Most of our patients used almost this amount after lunch the first day of sun exposure. The doses after one day of exposure shown in Table 1, excluding exposure time with sun5 screen, correspond well with the fact that 14 patients reported erythema. Though, no blistering erythema was reported. Harrison and Young (2002) indicated moderate sunburn to occur for doses of 5-8 SED and painful, blistering sunburn at 10 SED, for most white skin. For the remaining days with sun exposure, the patients spent varying degree and generally small amounts of sunscreen. They were asked to avoid sunscreen on the psoriasis lesions. To use all exposure time would therefore be reasonable when estimating the UV doses to the lesions. Furthermore, the body sites where the patients reported to have used sunscreen, were those susceptible to be sunburned. These sites were probably those receiving more than $50 \%$ of the available UV (Snellman, 1992 and Thieden, 2000).

15 The cumulative UV doses in Table 2 were estimated for the 15 days of sun exposure, whereas a regular treatment lasts for 21 days. The patients reached a plateau of daily sun exposure after the first week. Doses for a 3 weeks treatment period can therefore be estimated adding 6 days of exposure from the average of the last 5 days (day 1115). This would give a mean UV dose to the skin for 3 weeks treatment, starting in 20 March, of 253 SED $\left(2.53 \mathrm{~J} / \mathrm{cm}^{2}\right)$ or an ambient dose of 506 SED $\left(5.06 \mathrm{~J} / \mathrm{cm}^{2}\right)$. These doses are higher than those found by Snellman et al. (1992) for a 4 weeks treatment at the Canary Island in November 1989 (on average a skin dose of about $1.3 \mathrm{~J} / \mathrm{cm}^{2}$ ), and Vocks et al. (1989) for a 6 weeks treatment in Davos (ambient UVB dose of $1.4 \mathrm{~J} / \mathrm{cm}^{2}$ ). The doses are also higher than those found at the Dead Sea (ambient dose 17025390 SED or $1.70-3.90 \mathrm{~J} / \mathrm{cm}^{2}$ ) exposing the patients for only $3 \mathrm{~h}$ per day for 4 weeks (Even-Paz et al., 1996 and Even-Paz and Efron, 2003).

Interestingly, the psoriasis patients at Valle Marina seem to achieve good improvement also for other periods of the year, and with approximately the same sun exposure time. Figure 5 shows estimated doses for other time periods of the year when patients

UV doses during psoriasis climate therapy at Gran Canaria

L. T. N. Nilsen et al.

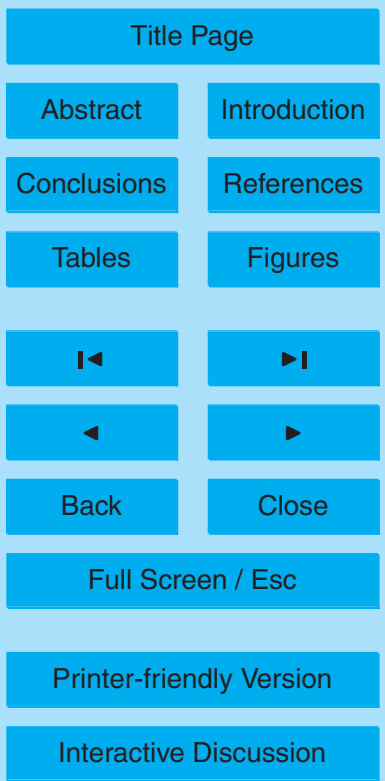


are sent to Valle Marina. It shows a factor 3 difference in UV dose between January and June. Patients treated in June may therefore receive higher doses than needed to achieve good therapeutic improvement.

Broadband UVB light therapy is given at the Rikshospitalet University Hospital in 5 Oslo. The CIE-weighted UVB dose used for skin type III is $0.03-0.05 \mathrm{~J} / \mathrm{cm}^{2}$ for the first exposure. The corresponding dose for the climate therapy patients the first day was in the same range as in the clinic, with a few patients receiving higher doses (Table 1).

The UV dose to the skin during a 3 weeks climate therapy (253 SED) is higher than the doses typically received by Danes during the whole year, estimated from personal 10 dosimeter measurements by Thieden et al. (2004) (median 173 SED, range 132 SED for indoor workers - 224 SED for gardeners). Sunbathing on the beach in Southern Europe showed just as high UV doses as for our patients (median 6.9SED per day, range 0.4-32.6 SED per day).

In conclusion, 3 weeks climate therapy at Gran Canaria resulted in $73 \%$ reduction in 15 PASI score. Estimated mean UV dose to the skin for the 15 days sun exposure was 165.8 SED. The individual percentual reduction in PASI score did not seem to depend on the UV dose. UV doses to our patients are higher than those received by climate therapy patients at other locations, in particular in May and June. It seems beneficial to use more strict exposure schedules that consider the available UV irradiance, depending on time of the day, time of the year and weather conditions.

Acknowledgements. The authors would like to thank Behandlingsreiser and Department of Dermatology at the Rikshopitalet Univerity Hospital, and The Norwegian Radiation Protection Authority (NRPA) for their support to carry out this study. In particular, the authors thank the personnel at the Norwegian Health Centre at Valle Marina. Furthermore, they would like to thank 25 A. Redondas at Instituto Nacional de Meteorologia (INM) for his kind support by calibrating the broadband sensors, O. Engelsen at the Norwegian Institute for Air Research, B. Johnsen and T. N. Aalerud at the NRPA, for valuable help with the radiation transfer model and Matlab programming. Last but very important, the authors thank all the patients participating in the study.

\section{ACPD}

8, 1-19, 2008

UV doses during psoriasis climate therapy at Gran Canaria

L. T. N. Nilsen et al.

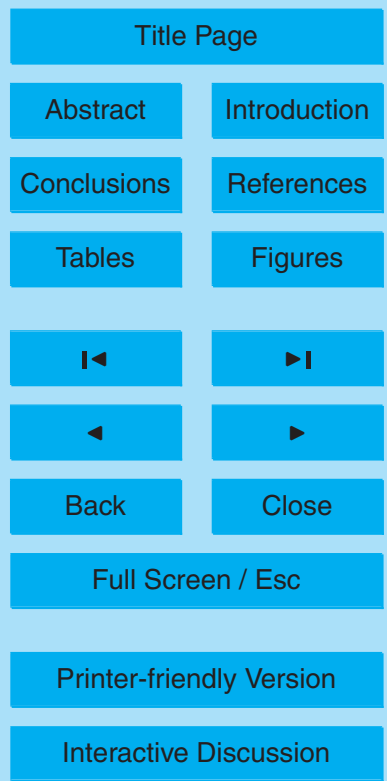




\section{References}

Abels, J. D. and Rose, T.: Treatment of psoriasis at a Dead Sea dermatology clinic, Int. J. Dermatol., 14, 134-137, 1995

Colipa: International Sun Protection Factor Test Method, The European Cosmetic Toiletry and Perfumery Association, 12, 2006.

Diffey, B. L., Larkö, O., and Swanbeck, G.: UV-B doses received during different outdoor activities and UV-B treatment of psoriasis, Brit. J. Dermatol., 106, 33-41, 1982.

Even-Paz, Z., Efron, D., Kipnis, V., and Abels, D. J.: How much Dead Sea sun for psoriasis, J. Dermatol. Treat., 7, 17-19, 1996.

10 Even-Paz, Z. and Efron, D.: Determination of Solar Ultraviolet Dose in the Dead Sea Treatment of Psoriasis, IMAJ, 5, 87-88, 2003.

Fitzpatrick, T. B.: The validity and practicality of sun-reactive skin types I through VI., Arch. Dermatol., 124, 869-871, 1988.

Fredriksson, T. and Pettersson, U.: Severe psoriasis - oral therapy with a new retinoid, Dermatologica, 157, 238-244, 1978.

Harrison, S. L. and Young, A. R.: Ultraviolet radiation-induced erythema in human skin, Methods, 28, 14-19, 2002.

Kushelevsky, A. P., Harari, M., Kudish, A. I., Hristakieva, E., Ingber, A., and Shani, J.: Safety of solar phototherapy at the Dead Sea, J. Am. Acad. Dermatol., 38, 447-452, 1998.

20 Mayer, B. and Kylling, A.: Technical note: The libRadtran software package for radiative transfer calculations - description and examples of use, Atmos. Chem. Phys., 5, 1855-1877, 2005, http://www.atmos-chem-phys.net/5/1855/2005/.

McKinlay, A. F. and Diffey, B. L.: A Reference Action Spectrum for Ultraviolet Induced Erythema in Human Skin, CIE-J, 6, 17-22, 1987.

NASA: Total ozone mapping spectrometer, http://toms.gsfc.nasa.gov/teacher/ozone_overhead. html, 2006.

Norges offentlige utredninger: Behandlingsreiser til utlandet, Et offentlig ansvar? NOU, 2, (in Norwegian), 2000.

Siekmann, H. and Aengenvoort, B.: Suitability of sunscreen for the prevention of skin cancer, BGIA-Report 3/2006e, 15, November 2006.

Sigmundsdottir, H., Gudjonsson, J. E., and Valdimarsson, H.: The effects of ultraviolet B treatment on the expression of adhesion molecules by circulating $T$ lymphocytes in psoriasis, Brit.

UV doses during psoriasis climate

therapy at Gran

Canaria

L. T. N. Nilsen et al.

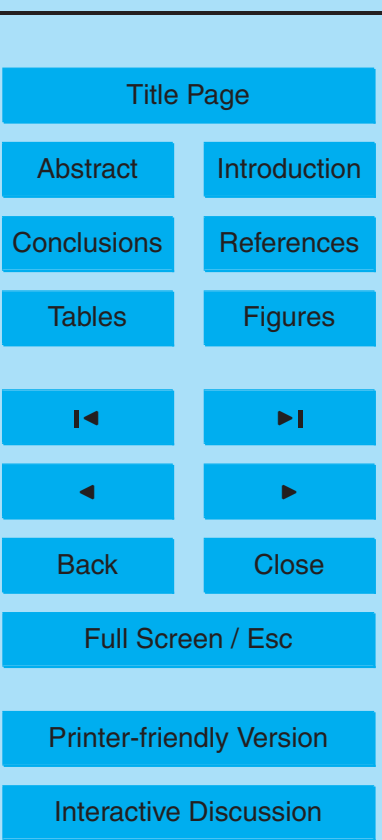


J. Dermatol., 148, 996-1000, 2003.

Sigmundsdottir, H., Johnston, A., Gudjonsson, J. E., and Valdimarsson, H.: Narrowband-UVB irradiation decreases the production of pro-inflammatory cytokines by stimulated $\mathrm{T}$ cells, Arch. Dermatol. Res., 297, 39-42, 2005.

5 Snellman, E., Jansèn, C. T., Lauharanta, J., and Kolari, P.: Solar ultraviolet (UV) radiation and UV doses received by patients during four-week climate therapy periods in the Canary Islands, Photodermatol. Photoimmunol. Photomed., 9, 40-43, 1992.

Thieden, E., Ågren, M. S., and Wulf, H. C.: The wrist is a reliable body site for personal dosimetry of ultraviolet radiation, Photodermatol. Photoimmunol. Photomed., 16, 57-61, 2000.

10 Thieden, E., Philipsen, P. A., Heydenreich, J., and Wulf, H. C.: UV Radiation Exposure Related to Age, Sex, Occupation, and Sun Behavior Based on Time-Stamped Personal Dosimeter Readings, Arch. Dermatol., 140, 197-203, 2004.

Vocks, E., Seifert, B., Hahn, H., and Fröhlich, C.: Quantitative assessment of heliotherapy in psoriasis vulgaris in high altitude climate, Z. Hautkr., 64, 466-472, 1989 (in German).

\section{UV doses during psoriasis climate therapy at Gran \\ Canaria}

L. T. N. Nilsen et al.

Title Page

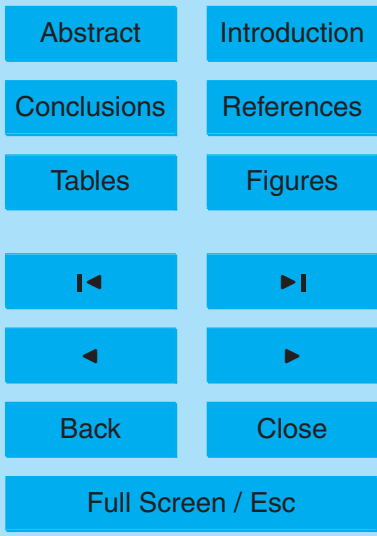

Printer-friendly Version

Interactive Discussion 
Table 1. Estimated UV doses to the patients after 1 day of sun exposure. Note: the values correspond to the respective ambient doses divided by 2 .

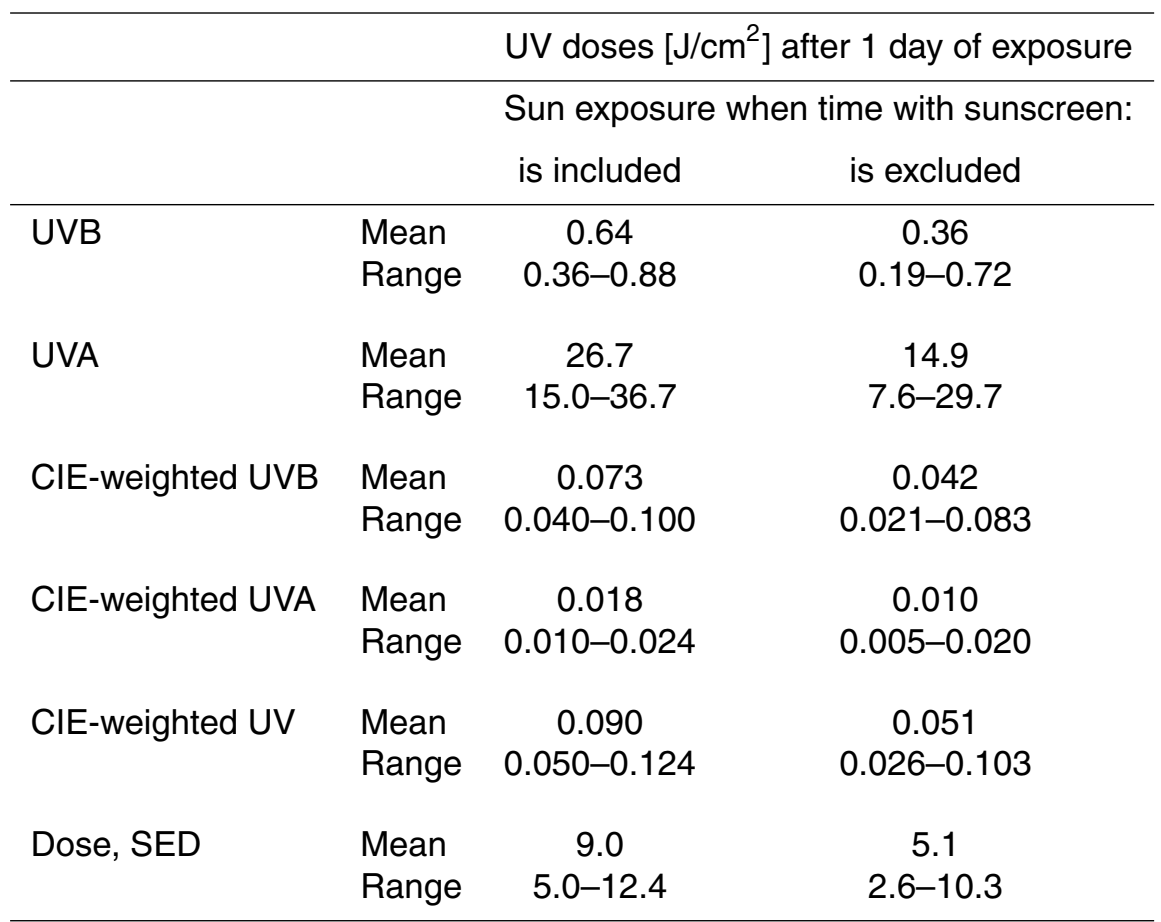

UV doses during psoriasis climate therapy at Gran

Canaria

L. T. N. Nilsen et al.

Title Page

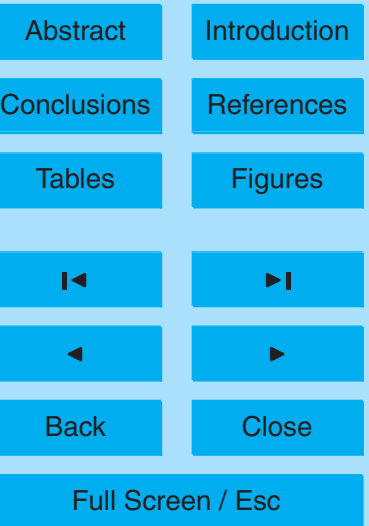

Printer-friendly Version

Interactive Discussion 
Table 2. Estimated cumulative UV doses received by the patients after 15 days of exposure. Note: the values correspond to the respective ambient doses divided by 2 .

\begin{tabular}{|c|c|c|c|}
\hline & & UV doses $[\mathrm{J} / \mathrm{C}$ & after 15 day of exposure \\
\hline & & Sun exposur & en time with sunscreen: \\
\hline & & is included & is excluded at day 1 \\
\hline UVB & Mean & 11.8 & 11.5 \\
\hline & Range & 7.4-14.6 & $7.2-14.6$ \\
\hline UVA & Mean & 464.2 & 452.4 \\
\hline & Range & $281.3-579.7$ & $273.6-579.7$ \\
\hline CIE-weighted UVB & Mean & 1.390 & 1.359 \\
\hline & Range & $0.884-1.723$ & $0.862-1.723$ \\
\hline CIE-weighted UVA & Mean & 0.306 & 0.298 \\
\hline & Range & $0.186-0.382$ & $0.181-0.382$ \\
\hline CIE-weighted UV & Mean & 1.696 & 1.658 \\
\hline & Range & $1.069-2.101$ & $1.043-2.101$ \\
\hline Dose, SED & Mean & 169.6 & 165.8 \\
\hline & Range & 107.0-210.1 & $104.3-210.1$ \\
\hline
\end{tabular}

UV doses during psoriasis climate therapy at Gran

Canaria

L. T. N. Nilsen et al.

Title Page

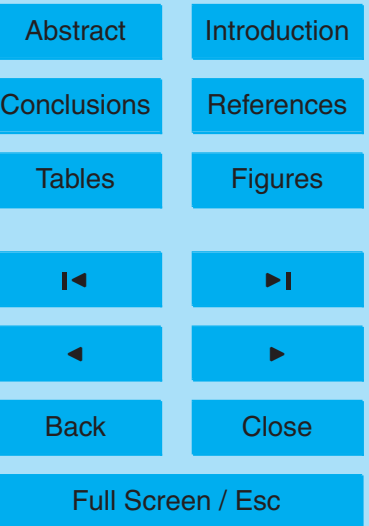

Printer-friendly Version

Interactive Discussion 


\section{ACPD}

8, 1-19, 2008

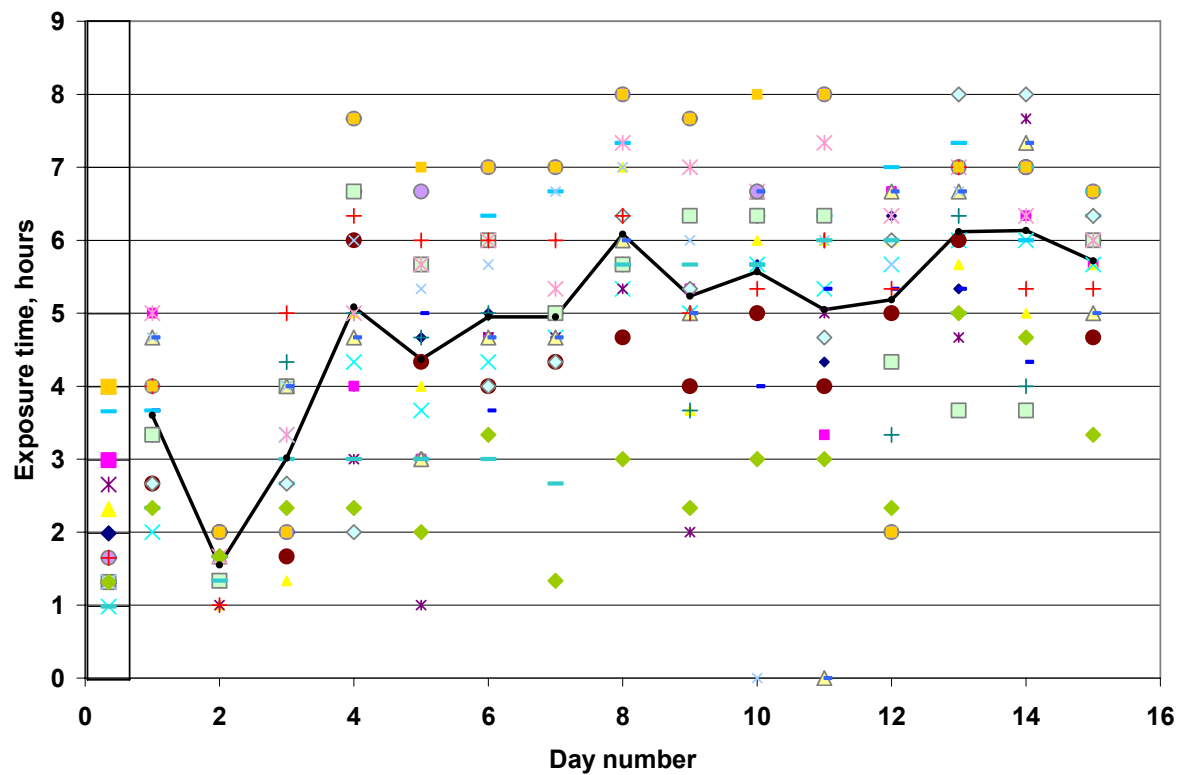

UV doses during psoriasis climate therapy at Gran Canaria

L. T. N. Nilsen et al.

Title Page

Abstract

Introduction

Conclusions

References

Tables

Figures

14

$\rightarrow$

4

Back

Close

Full Screen / Esc shown as the black line. The exposure times corrected for the use of sunscreen on day 1 are indicated by a rectangle.

Printer-friendly Version

Interactive Discussion 


\section{ACPD}

$8,1-19,2008$

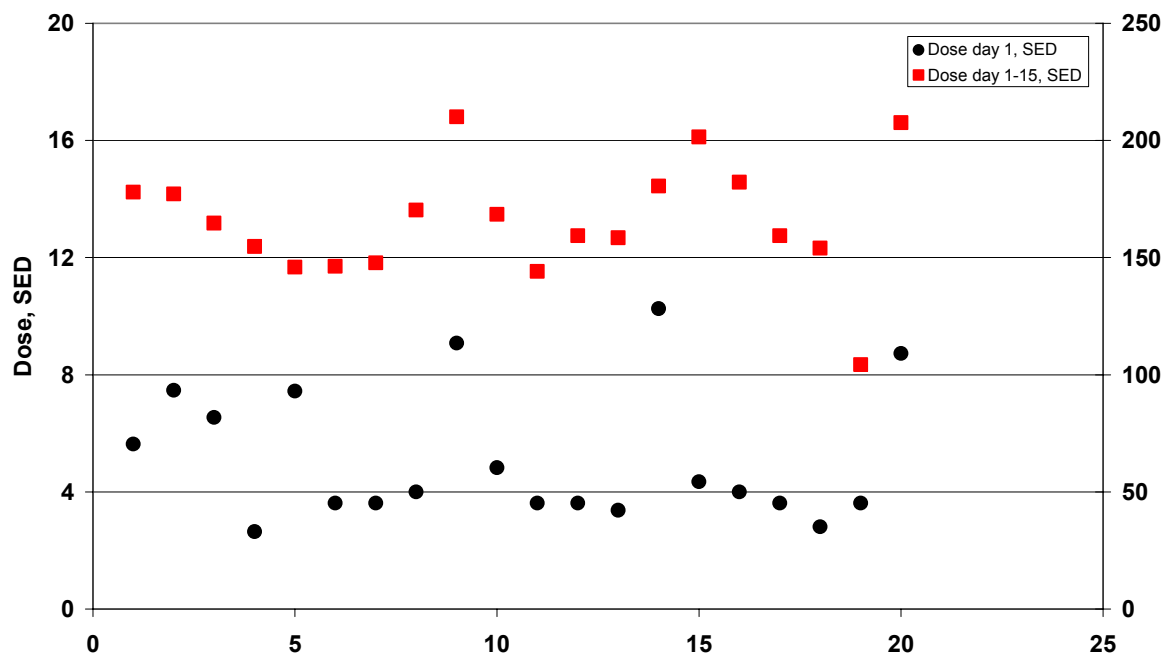

\section{UV doses during psoriasis climate therapy at Gran \\ Canaria}

L. T. N. Nilsen et al.

Fig. 2. UV doses estimated for each patient on the first day of sun exposure (black circles, left axis) and for the whole period of sun exposure (day 1 to 15; red squares, right axis). The doses correspond to the ambient doses divided by 2 .

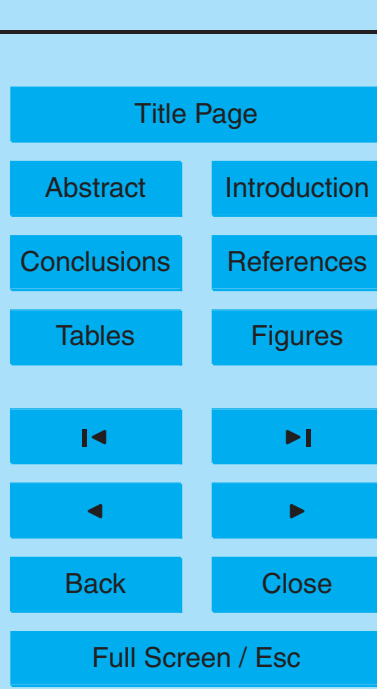

Printer-friendly Version

Interactive Discussion 


\section{ACPD}

$8,1-19,2008$

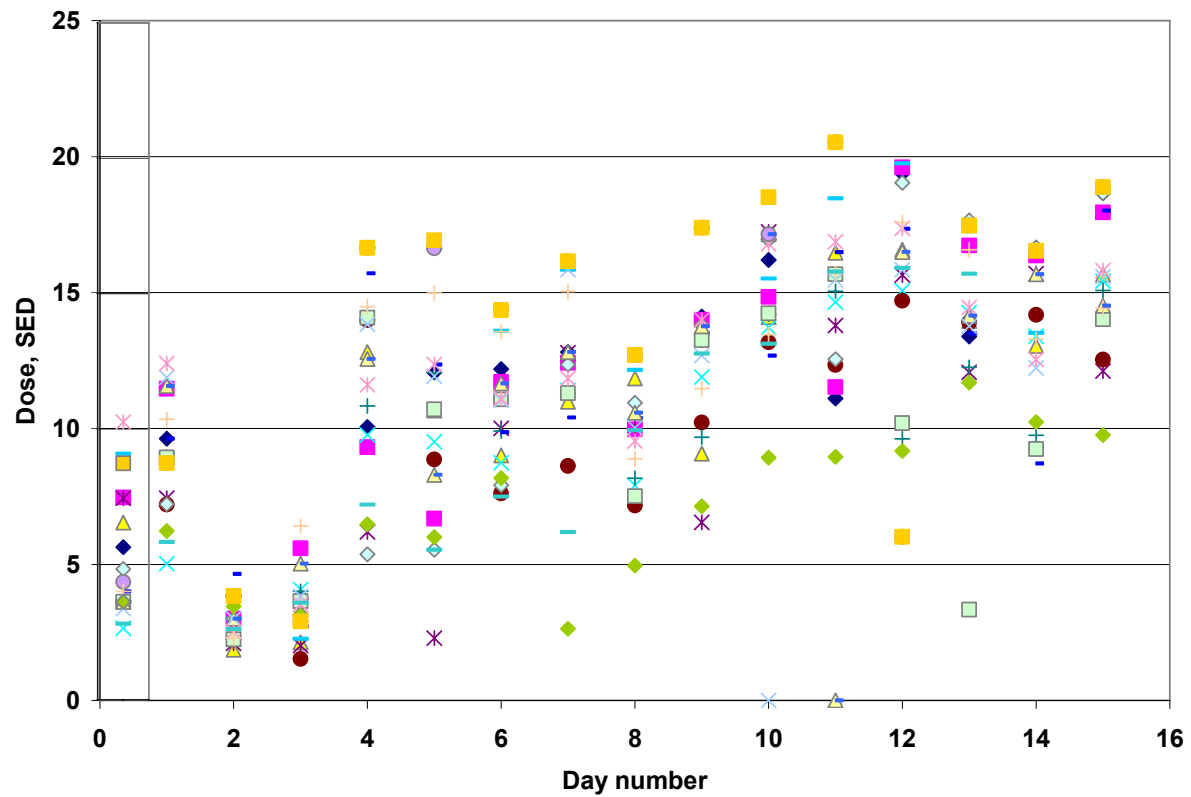

UV doses during psoriasis climate therapy at Gran Canaria

L. T. N. Nilsen et al.

Title Page

Abstract

Conclusions

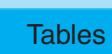

14

4

Back
Introduction

References

Figures

$\rightarrow 1$

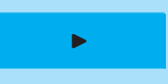

Close

Fig. 3. UV doses estimated for each patient for each day. The doses correspond to the ambient doses divided by 2 . The rectangle marking the data points before day 1 indicates the doses excluding exposure time under the application of sunscreen.

Full Screen / Esc

Printer-friendly Version

Interactive Discussion 


\section{ACPD}

8, 1-19, 2008

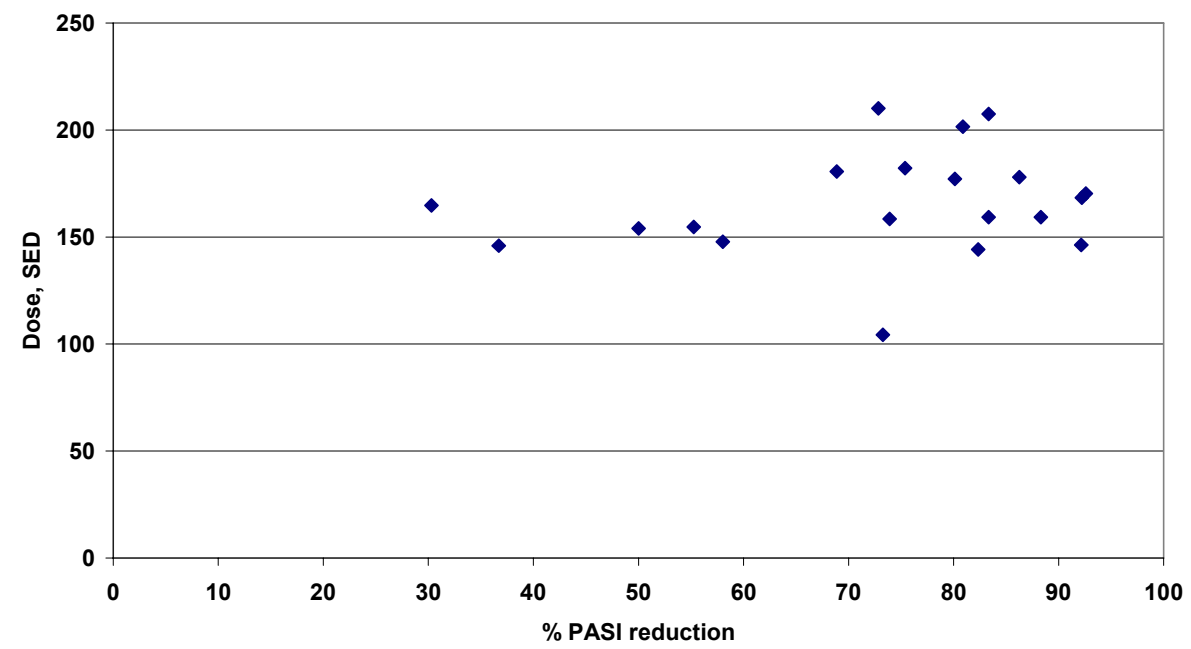

Fig. 4. The cumulative UV dose did not show relation to the percentage improvement in PASI score.

\section{UV doses during psoriasis climate therapy at Gran Canaria}

L. T. N. Nilsen et al.

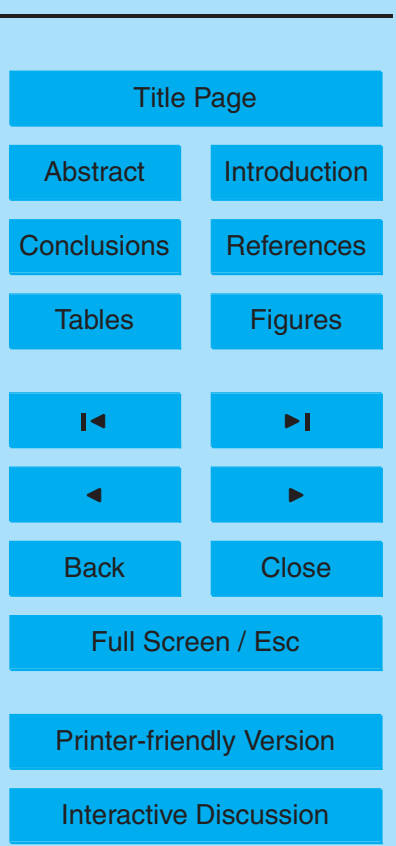




\section{ACPD}

$8,1-19,2008$

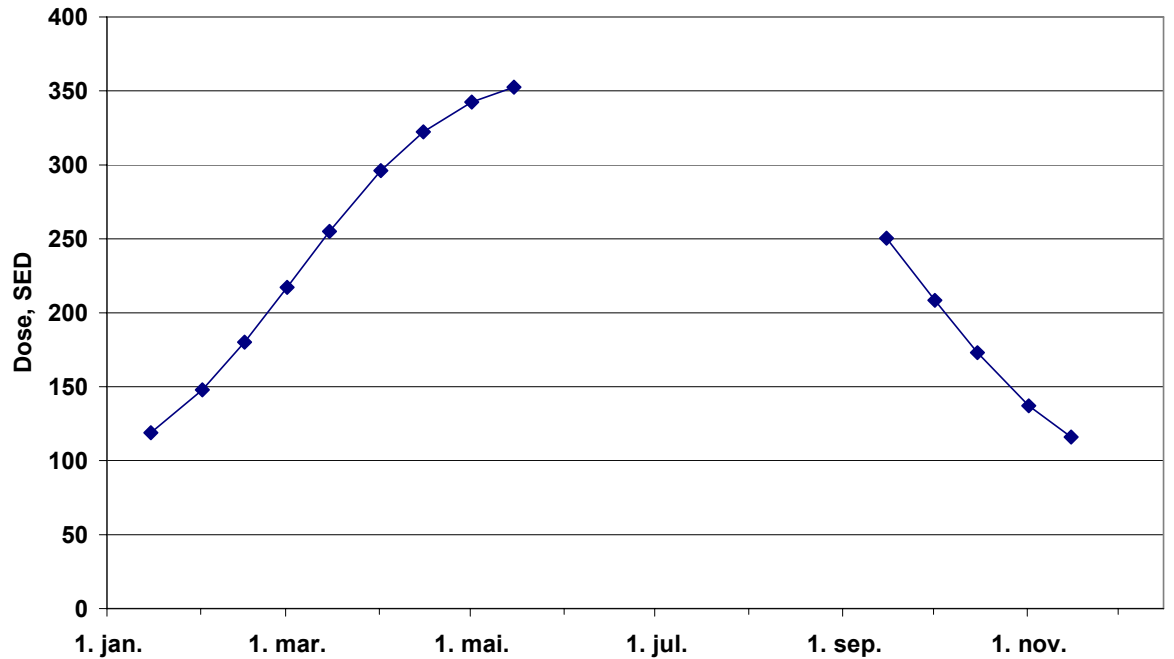

UV doses during psoriasis climate therapy at Gran Canaria

L. T. N. Nilsen et al.

Title Page

Abstract Introduction

Conclusions

References

Tables

Figures

14

$\rightarrow$

4

Fig. 5. Estimated UV doses for a full treatment period of 21 days depending on the time of the year. The doses are estimated using the sun exposure schedule, weather conditions and ozone values as for the study in March 2006. Doses are calculated as the ambient doses divided by 2.

Back

Close

Full Screen / Esc

Printer-friendly Version

Interactive Discussion 